\title{
Addenda a «El Templo Romano de Barcelona»
}

Juan Bassegoda Nonell *

El 31 de octubre de 1974 se terminó de imprimir el libro El Templo Romano de Barcelona, editado con motivo del 125 aniversario de la Real Academia de Bellas Artes de San Jorge de Barcelona.

En este volumen se comentaba la Memoria de Antonio Celles Azcona, escrita en 1835, sobre lo que entonces se tenía por templo de Hércules, en la cumbre del Mons Taber de Barcelona. Dicha Memoria había permanecido inédita, salvo un breve extracto en 1884, hasta aquel momento.

La continuada investigación ha permitido añadir a aquel trabajo algunos puntos clarificadores, inéditos o no, que conviene ahora reunir en esta Addenda.

En 1975 se publicó un artículo en La Vanguardia Española de Barcelona a raíz de un estudio topográfico del Mons Taber barcelonés. Esta tarea de medición y topografía permitió obtener un plano exacto de la trama urbana de la ciudad antigua, al que se superpuso la planta ideal del templo romano en su exacta ubicación. Otros intentos en este sentido se habian realizado anteriormente con menos exactitud.

Pi y Arimón publicó un plano de las murallas de Barcelona y de la situación del templo, pero sin las calles existentes en su tiempo. El plano, además de ser de pequeño tamaño, contiene errores considerables.

* Escuela Técnica Superior de Arquitectura, Barcelona. 
Pedro Domènech Roura realizó en 1929 un dibujo de la ciudad romana con el templo y el trazado de las calles, pero la situación del monumento es también errónea.

Otro intento realizado por la señorita Pallarés resultó igualmente fallido por haber tomado las medidas del intercolumnio de una falsa cota existente en uno de los dibujos de Celles.

Disponiéndose ahora de la exacta situación del tempio en el Barrio Gótico, merced al dibujo del Aparejador don José M. ${ }^{a}$ Jansà, se aprecian ciertas particularidades que, por lo notorias, bien merecen un comentario.

La calle del Paradís tiene forma de cuatro y en su trazado avanza desde el ábside de la catedral, penetrando lateralmente en la cella del templo, haciendo su primera inflexión de noventa grados justo frente a la puerta de Centre Excursionista de Catalunya, donde está embebida en el pavirnento una rueda de molino que indica, según la tradición, el punto más alto del Mons Taber. Así es, pero además, esta rueda se halla casi matemáticamente situada en el centro de la cella del templo, lo cual no deja de ser una extraordinaria casualidad. Hay que tener en cuenta, sin embargo, que la rueda está colocada un metro y medio por debajo del nivel del pavimento del templo. Una vez cambiada la dirección, la calle Paradis, sigue exactamente el eje mayor del templo, pasando por la puerta de la cella, por en medio de las dos columnas de la fachada delantera, luego de hacerlo por las dos in antis de la cella. Luego cambia de dirección otros noventa grados y desciende hasta la plaza de San Jaime, paralelamente a la fachada del templo y a la calle del Obispo Irurita, que se supone fuera el Decumanus Maximus de la ciudad. Por lo tanto entre dicha calle y la escalinata del templo debió existir una pequeña plaza ocupada ahora por edificios modernos. Esta forzada situación de la medieval calle de Paradís viene perfectamente obligada por el templo y es un interesante ejemplo de trazado urbanístico medieval superpuesto a un templo romano. La parte central de la calle es en realidad una Vía Sacra que cruza la mitad delantera del templo y cambia, reverentemente, de dirección al encontrarse delante de la imagen que debió presidir el Sancta Sanctorum del templo. Mucho se ha discutido sobre la toponimia de la calle Paradís, ahora a las muchas hipótesis se podría añadir la de una calle que penetra dentro de un templo donde debe suponerse que, por ser habitación de los dioses, se halla el paraiso.

El plano en cuestión ha costado medio año de trabajo y un considerable esfuerzo económico pero puede ser una valiosa ayuda para los arqueólogos y también para los estudiosos del urbanismo medieval. 
En 1980 el encargado de la Sección de Grabados y Dibujos de la Biblioteca de Catalunya, Francesc Fontbona, comunicó al autor de El Templo Romano de Barcelona el hallazgo de los planos que acompañaban la memoria de José Mariano de Cabanes, publicada en 1838. Tales dibujos son copia de los que realizó Celles en 1835 y son los siguientes:

1. Croquis del alzado frontal de templo. (El gemelo de este, por Celles, fue publicado en El templo romano, pág. 126.)

2. Croquis del alzado lateral del templo. (El templo, pág. 115.)

3. Planta del templo en forma de croquis. (El templo, pág. 110.)

4. Cornisas a la aguada. (El templo, pág. 169; publicado también por Balil en Las murallas romanas de Barcelona, pág. 34.) 22.)

5. Cornisa a la aguada (El templo, pág. 163 y Las murallas, pág.

6. Planta de la muralla del Palao. (El templo, pág. 165, Las murallas, pág. 22.)

7. Alzado y planta murallas Tapinería. (El templo, pág. 164 y Las murallas, pág. 23.)

8. Alzado y planta de la calle Basea. (El templo, pág. 164, Las murallas, pág. 23.)

9. Alzado y planta Enseñanza. (El templo, pág. 167, Las murallas, pág. 22.)

10. Planta general. (El templo, pág. 161, Las murallas, pág. 21.)

Con este hallazgo se enriquece la colección de dibujos sobre templo y murallas y se completa el conocimiento del estudio iniciado por Celles y continuado por Cabanes.

El libro de 1974 contiene una detallada biografía de Celles y de su obra arquitectónica. Entonces se publicó la planta de la Iglesia de las Carmelitas de la calle del Hospital (1831) conocida por el plano de "Quarterons" de Miguel Garriga Roca (1859). En 1983, procedente del despacho del arquitecto José Domènech Estapà (1858-1917), y por donativo de su nieto Enrique, ingresó en el archivo de la Cátedra Gaudí un dibujo a la aguada de la fachada de la Iglesia del convento de la Encarnación de las Madres Carmelitas en la calle del Hospital. Se ignora la razón de su presencia en el archivo de Domènech Estapà. 


\section{JUAN BASSEGODA NONELL}

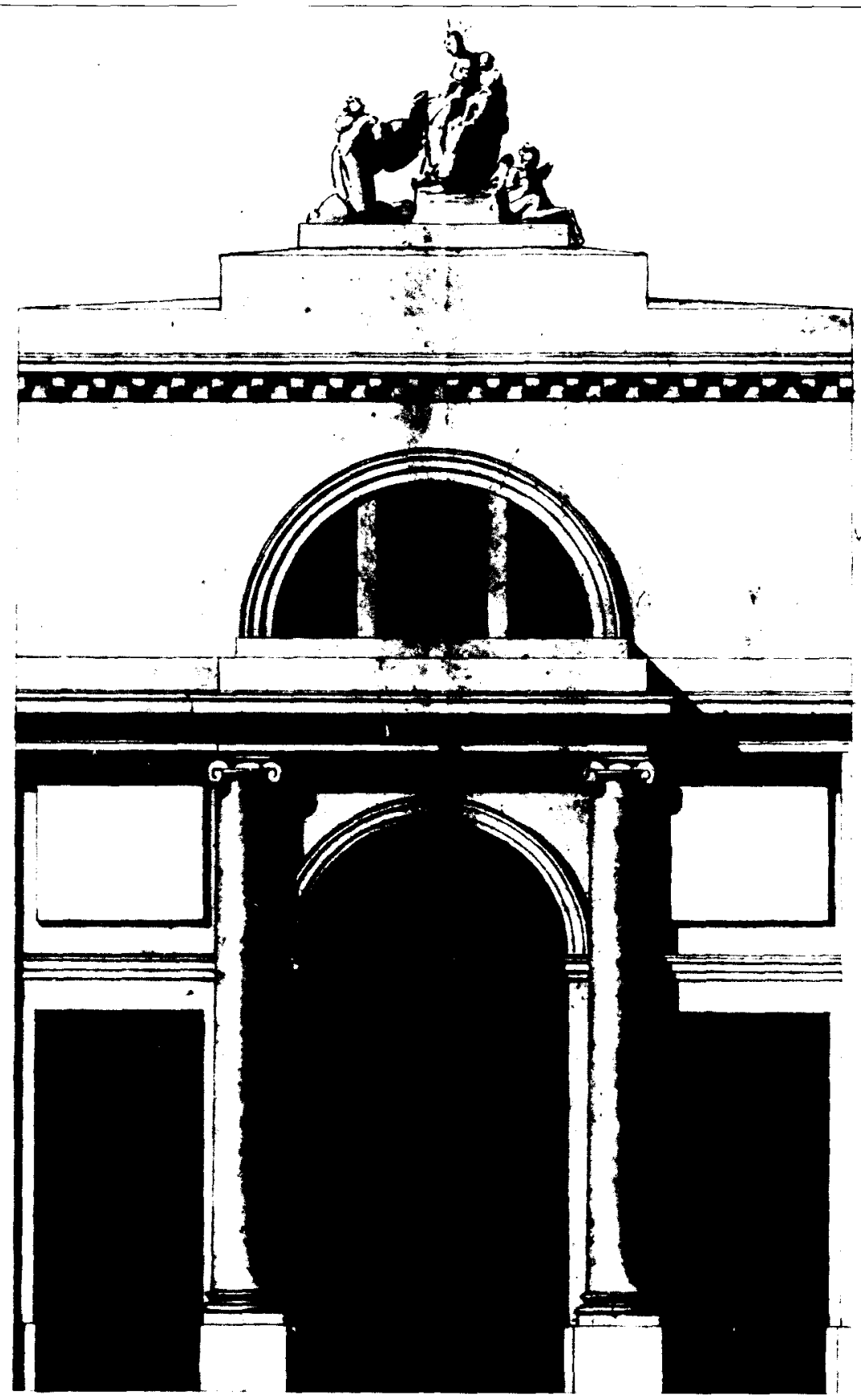

Fig. 1. Fachada de la nueva iglesia de las MM. Carmelitas Calzadas de BarceIona (Antonio Celles, 1830). 
El plano lleva una leyenda que dice: "Fachada de la nueva iglesia de las MM. Carmelitas Calzadas de Barcelona", con escala gráfica o petipié en palmos y la fecha, Barcelona, 4 de julio de 1830. Además se puede leer: "Hecho por el arquitecto académico de Mérito don Antonio Celles», rubricado y una "Aprobación de la Real Academia de San Fernando en Junta Ordinaria de 22 de agosto de 1830", firmado por el vicesecretario Juan $M$. de Inclán Valdés. Presenta un dibujo del alzado de un pórtico in antis con columnas exentas jónicas y tres serlianas, con ático superior palladiano de hueco semicircular, cornisa con modillones y un grupo escultórico de remate que representa a la Virgen del Carmen entregando el escapulario a San Simón Stock.

Este dibujo fue a dado a conocer en un artículo en La Vanguardia el 23 de septiembre de 1983 y en otro, más pormenorizado, en el Boletín de la Real Academia de San Fernando, N. 56 (1983).

Otros planos de Celles inéditos fueron localizados en el Archivo Histórico del Colegio de Arquitectos de Barcelona. Corresponden al proyecto de restauración de la iglesia del Monasterio de Montserrat en 1829. Fueron expuestos en dicho Colegio de Arquitectos y uno de los dibujos, que representa la sección longitudinal de la iglesia, fue reproducido en el cartel anunciador de la exposición, que se celebró del 22 al 30 de agosto de 1979.

Otro dibujo de Celles, no mencionado en El Templo romano de Barcelona, es el que se expuso en el Museo Martorell de Barcelona en 1883, dentro de la muestra organizada por la Asociación Artística y Arqueológica de Barcelona. Era un proyecto de Casa de Contratación, sin fecha, y era propiedad en 1883 de don Federico Fontserè.

Con este conjunto de noticias se redondea el estudio de 1974 y se demuestra, una vez más, que una investigación sobre historia de arquitectura y arqueología, jamás queda cerrada. 


\section{BIBLIOGRAFÍA}

Bassegoda Nonell, J., 1974: El Templo Romano de Barcelona. Real Academia de Bellas Artes de San Jorge, Barcelona.

-, 1975: La situación del templo romano de Barcelona. La Vanguardia Española, 17 de junio de 1975, pág. 28. Barcelona.

Cabanes, J. M. DE, 1838: Memoria sobre el templo de Hércules. Imprenta de la Viuda e Hijos de Antonio Brusi. Barcelona.

BALIL, A., 1961: Las Murallas romanas de Barcelona. Supl. de Archivo Español de Arqueología, C.S.I.C. Madrid.

Bassegoda Nonell, J., 1983: El pórtico del convento de Carmelitas. La Vanguardia, 22 de septiembre de 1983. Barcelona.

-, 1983: Arquitectura neoclásica de Barcelona. Boletín de la Real Academia de Bellas Artes de San Fernando, n. ${ }^{\circ} 56$, págs. 83-87, Primer Semestre de 1983. Madrid.

Album de dibujos de la Asociación Artística y Arqueológica. Barcelona 1883, pág. 34. 